\title{
The Mechanisms App: Electron-pushing formalism as a software system
}

Julia E. Winter, ${ }^{*} \dagger$ Sarah E. Wegwerth, ${ }^{\dagger}$ Gianna J. Manchester, ${ }^{\dagger}$ Michael T. Wentzel,,${ }^{\ddagger}$ Michael J. Evans, ${ }^{\partial}$ James E. Kabrhel, \# Lawrence J. Yee $\S$

$\nmid$ †lchemie Solutions, Inc, 950 Stephenson Highway, Troy, MI 48083

¥Augsburg University, 2211 Riverside Ave, Minneapolis, MN 55454

${ }^{\circ}$ Georgia Institute of Technology, North Ave NW, Atlanta, GA 30332

\#University of Wisconsin - Green Bay, Sheboygan Campus, 1 University Drive, Sheboygan, WI 53081

§Hartnell College, 411 Central Ave, Salinas, CA 93901

\section{ABSTRACT}

The arrows depicting electron movement and the bond-making and breaking events are the maps that guide student instruction in organic chemistry curricula. For students, the pathways represented by electron pushing formalism $(\mathrm{EPF})$ can be tough to navigate. For instructors, providing formative feedback to students to support their learning of the EPF arrow system is difficult to provide in a timely manner. The Mechanisms app ("Mechanisms”) was developed as a method for students to explore the electron movement of organic chemistry through a touch screen interface of a smart phone or tablet and do so within a game-like experience. In this paper the pedagogical content of the Mechanisms app ("Mechanisms") is described along with studies of students' use of the app to understand whether the open-ended experience to construct understanding of EPF is valuable as a formative assessment method. Presented in this paper are the results of Mechanisms use by analysis of a multi-institution anonymous student survey, with a usability study of organic chemistry students, and with three case studies detailing the use of the app in college classrooms. 


\section{KEYWORDS}

Upper-Division Undergraduate, Second-year Undergraduate, Organic Chemistry, Constructivism, Mechanisms of Reactions, Computer-Based Learning

\section{INTRODUCTION}

The arrows depicting electron movement and bond-making and breaking events are the maps that guide student instruction in organic chemistry curricula. In the hands of experts, the curved arrows can be used to explain and predict reaction pathways. ${ }^{1}$ Too often for students, including graduate students, the routes through organic reactions seem to be filled with dead ends and roadblocks. ${ }^{2-4}$ Even when students are given the destination - the product of the reaction - they can be more likely to adopt incorrect reasoning to describe the mechanistic steps of the reaction path. ${ }^{5-7}$

The question becomes how best to help students understand the electron-pushing formalism (EPF) of organic chemistry and move beyond memorizing a procedure to explaining a process. ${ }^{8-14}$ Research has shown that novice learners in organic chemistry focus on surface features when presented with an organic reaction while experts "see" deeper concepts during each step of a mechanistic pathway. ${ }^{15,16}$ Recent studies have shown that the use of animations help students to move to a this more dynamic, and expert view, of reactions. ${ }^{17}$ The Mechanisms app, by Alchemie, was developed to allow students to experiment and "play" with the electrons and bonds of organic chemistry to make sense of the EPF in a game-like experience..$^{4,18}$

The original hypothesis that grounded the app's development was inspired by Jerome Bruner's theory of constructivism, and that if students could interact with and get immediate feedback from a software system that presented EPF on a touchscreen, they would be more likely to reason through the mechanisms of organic chemistry. Bruner was a proponent for discovery-based learning through careful scaffolding of material. ${ }^{19}$ Based on this theory, the Mechanisms app was developed as an environment for exploring mechanistic pathways with varying levels of scaffolding provided by the task cards, goals, immediate move assessment, and hints. 
In this paper the content of the Mechanisms app ("Mechanisms") is described. Also presented are the results from a multi-institution student survey, a usability study of organic chemistry students, and three case studies detailing the use of the app in college classrooms.

\section{MECHANISMS CONTENT}

Mechanisms was first released in spring 2018 with a tutorial system and 60 interactive exercises ("puzzles"), 20 each in the reaction categories Acid/Base, Addition, and Carbonyls. Currently the software system has 250 puzzles, divided into the following sections: Tutorial, Essentials, Substitution and Elimination Reactions, Oxygen-Containing Functional Groups, and Pi Systems (Table 1).

Table 1. Pedagogical content in the sections of Mechanisms

\begin{tabular}{|l|l|l|}
\hline Section & Categories & Details \\
\hline Tutorial (How to Play) & $\begin{array}{l}\text { Movement, Electrons \& Bonds, } \\
\text { Formal Charge, Decision Point, } \\
\text { Interface }\end{array}$ & $\begin{array}{l}\text { Interactive tutorials introducing } \\
\text { the UI of the app and describing } \\
\text { how to use. }\end{array}$ \\
\hline $\begin{array}{l}\text { Essentials } \\
\text { (100 puzzles) }\end{array}$ & $\begin{array}{l}\text { Intro Reactions, Structure, Acid } \\
\text { Base Reactions, Addition } \\
\text { Reactions, Carbonyl Reactions }\end{array}$ & $\begin{array}{l}\text { An overview from both semesters of } \\
\text { organic chemistry to try out the } \\
\text { app and learn content }\end{array}$ \\
\hline $\begin{array}{l}\text { Substitution and Elimination } \\
\text { (60) puzzles) }\end{array}$ & $\begin{array}{l}\text { Substitution Reactions, } \\
\text { Elimination Reactions, and a } \\
\text { combined section with both types } \\
\text { of reactions }\end{array}$ & $\begin{array}{l}\text { The puzzles are divided into Sn } 1 / 2 \\
\text { and then E1/E2, in the combined } \\
\text { section students must decide } \\
\text { which of the 4 pathways is favored. }\end{array}$ \\
\hline $\begin{array}{l}\text { Oxygen-containing Functional } \\
\text { Groups } \\
\text { (60 puzzles) }\end{array}$ & $\begin{array}{l}\text { Alcohol Reactions, Aldehyde and } \\
\text { Ketone Reactions, Carboxylic Acid } \\
\text { Reactions }\end{array}$ & $\begin{array}{l}\text { A broad survey of the mechanisms } \\
\text { of these functional groups }\end{array}$ \\
\hline $\begin{array}{l}\text { Pi Systems } \\
\text { (40 puzzles) }\end{array}$ & $\begin{array}{l}\text { Triple Bond Reactions, } \\
\text { Electrophilic Aromatic Substitution } \\
\text { (EAS) Reactions }\end{array}$ & $\begin{array}{l}\text { The triple bond reactions category } \\
\text { contains content from both } \\
\text { semesters. }\end{array}$ \\
\hline
\end{tabular}

Each of the puzzles has its own short video (30 - 90 seconds) that can be accessed from within the app. A web-based instructor dashboard allows faculty to assign sets of puzzles for either in-class or out-of-class work. These assignments are delivered as a separate category in the app on the students' device. The app is free to download from the AppStore and Google Play. ${ }^{20}$ To accommodate students without access to smartphones or tablets, Mechanisms is available as a web-based product. ${ }^{21}$ The Tutorial and 50 puzzles of the Essentials section are free to use, the remaining content of 200 puzzles is available for $\$ 9.99$. A spreadsheet detailing the content of all the categories, reaction puzzles, reaction schemes, and concepts covered in the app is provided in Supporting Information (SI). 
The EPF interaction of Mechanisms does not include any arrows. This was a decision made during early development as on a touchscreen even if there were an arrow when electrons are moved from source to sink, the head of an arrow would not be visible underneath a finger on the screen (Figure 1). The arrow showing direction of the electron flow is actually not necessary, as the direction of the electron movement is always from the source. For example, a user can reveal hidden electrons from nucleophile with a tap and then drag them to make a bond with the electrophile, but there is no way to move the electrons in the opposite direction.
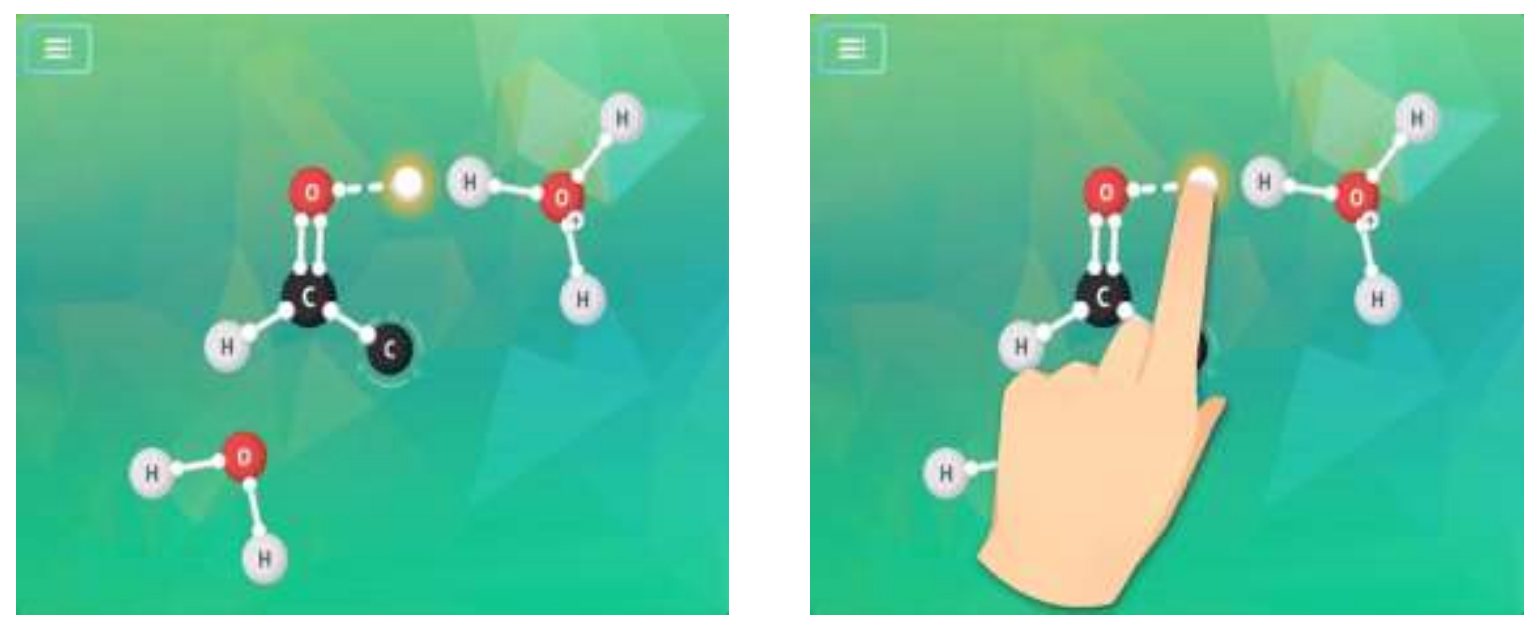

Figure 1. User interaction for electron movement on a touchscreen.

\section{Scaffolding Features}

The formative feedback of gameplay is delivered to students through visuals, text, and sounds

(Figure 2). Every puzzle starts with a task card. Most of these cards include images of curved arrows for one of the mechanistic steps the student will encounter during the reactions. Students can access a list of goals (examples are, "form the more stable carbocation", "show the resonance delocalization", "perform a nucleophilic attack") at any time during game play. Immediate move assessment happens when a move is not allowed; the bond snaps back into position and delivers a "cat hiss" correction sound. Sometimes this correcting feedback is accompanied by a hint button, which give specific instructions on why a move is incorrect. When the puzzle is complete, a "Goals Achieved" sign appears, and an explosion of stars are seen on the goal card. 

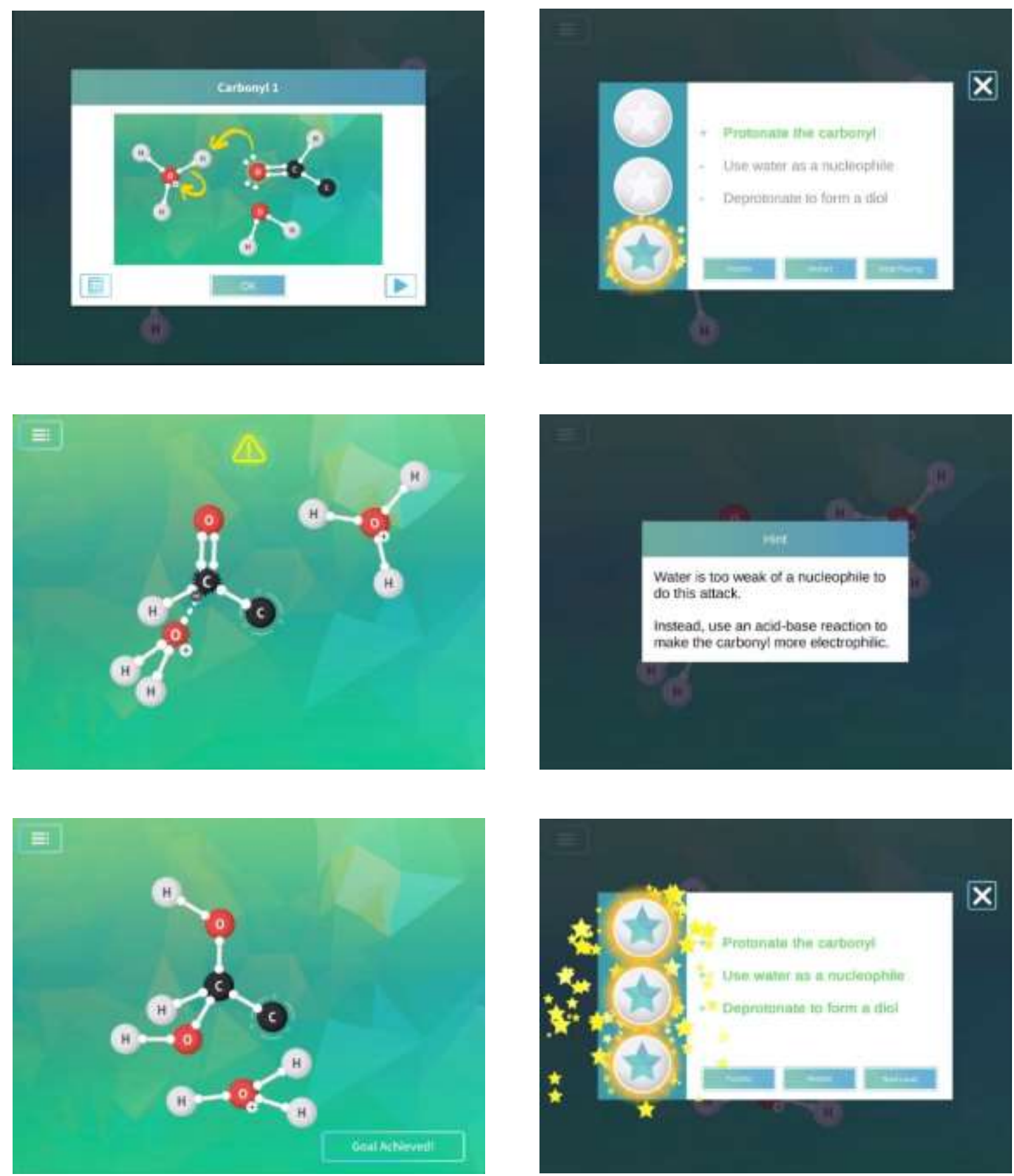

Figure 2. Scaffolding features of Mechanisms from top left, a) Task Card, b) Goals of puzzle, c) Immediate move assessment , d) Hint after incorrect move, e) Final product with Goal Achieved Feedback, f) Explosion of stars when goals are achieved.

The challenge to the pedagogy and development team has been to build enough scaffolding for novice learners, while allowing the spirit of experimentation and hypothesis-testing to be part of the experience. An "expert mode" feature, which removes goals, hints, and videos, was added to allow 
students to test their understanding without the extra help. In order to find that balance between supported and open-ended gameplay, the team looked to student users for guidance.

\section{STUDENT USE SURVEY}

During the 2018 - 2019 academic year Mechanisms was used in 55 institutions. An anonymous survey was distributed to students at 19 of those institutions (Figure 3). The results from the 387 student responses, collected between December 2018 and May 2019, were used to guide development of features with the app.

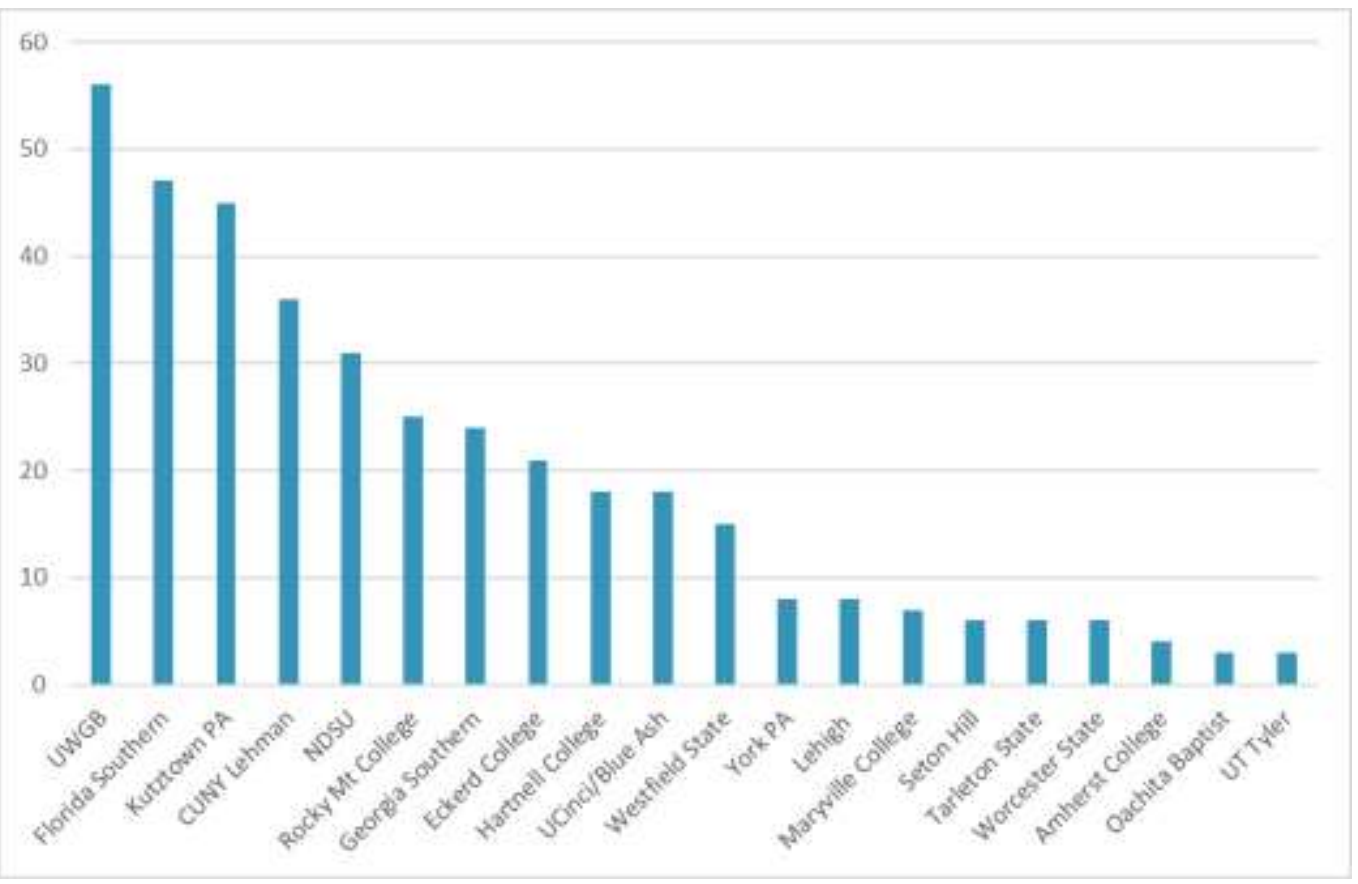

Figure 3. Institutions participating in student survey during 2018 - 2019 academic year.

The goal of the survey was to improve the student experience. To determine which features were most important to students, we first divided the survey respondents into groups with respect to how they answered the question: How would you feel if Mechanisms was no longer available? ${ }^{22}$ Of the 387 students, 48 would be very disappointed, 215 would be somewhat disappointed, and 124 would not be disappointed.

Once the groups were segmented into these three groups, the open-ended responses to the survey question regarding the benefits of the app and suggestions for improvements were coded and analyzed 
(Figure 4 and Table 2). The value of this approach in terms of product development is to understand what the more engaged students feel are the needed improvements for the technology and the features that are most used.
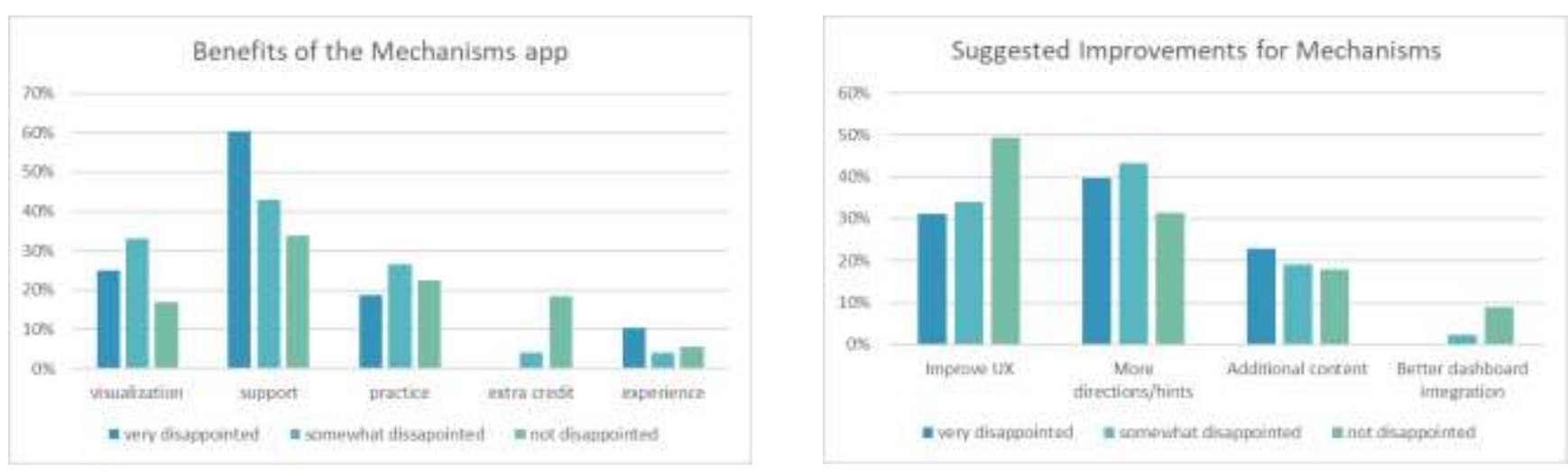

Figure 4: Responses from open-ended questions by students in Mechanisms use survey, as a percentage of the total in each segment : very disappointed, somewhat disappointed, and not disappointed.

Table 1. Representative comments from students in survey

\begin{tabular}{|l|l|}
\hline Visualization & It is helpful for seeing how bonds actually look in real time as they move. \\
\hline Support & $\begin{array}{l}\text { It helps me understand the atom to atom connectivity in the reactions \& identify } \\
\text { important patterns. }\end{array}$ \\
\hline Practice & Unlimited chances to get the right answer \\
\hline Experience & I love how it is interactive \\
\hline Improve UX & Using the app on a cellphone is hard since the atoms are small \\
\hline More directions/hints & $\begin{array}{l}\text { Provide a help system so when students are struggling, it guides them in the reaction } \\
\text { process }\end{array}$ \\
\hline Additional Content & More reactions. Concept checking. Basic reaction type tutorial. \\
\hline $\begin{array}{l}\text { Better dashboard } \\
\text { integration }\end{array}$ & $\begin{array}{l}\text { When the professor assigns certain mechanisms to be completed, have an assignment } \\
\text { section within the app so they do not have to send out a list. }\end{array}$ \\
\hline
\end{tabular}

Due to this student feedback and through discussions with faculty, further development in 2019 added the introductory section of 10 puzzles for basic concepts, videos to accompany all puzzles, more hints were added to game play, and improved assignment integration was built into the app. For faculty use, the dashboard included more specifics about the reactions in the puzzles and a curriculum was devised for using the app in an active learning environment.

\section{AUGSBURG UNIVERSITY USABILITY SURVEY}

In the spring of 2019 six students were recruited for think-aloud interviews, all students were in second semester organic chemistry, and the study was conducted the week before the final exam. The 
primary research question was: How do students utilize and respond to the formative feedback and instructional cues in both non-expert and expert modes while using Mechanisms?

All student testing and data analysis was approved as ethical by Augsburg University's IRB \#201924-03. Arbitrarily, half of participants used the app in non-expert mode (N1, N2, and N3) and half used expert mode (E1, E2, and E3) to work through Aldehyde and Ketone 13, an aldol reaction of acetone with benzaldehyde. All students had used Mechanisms for class prior to the interviews.
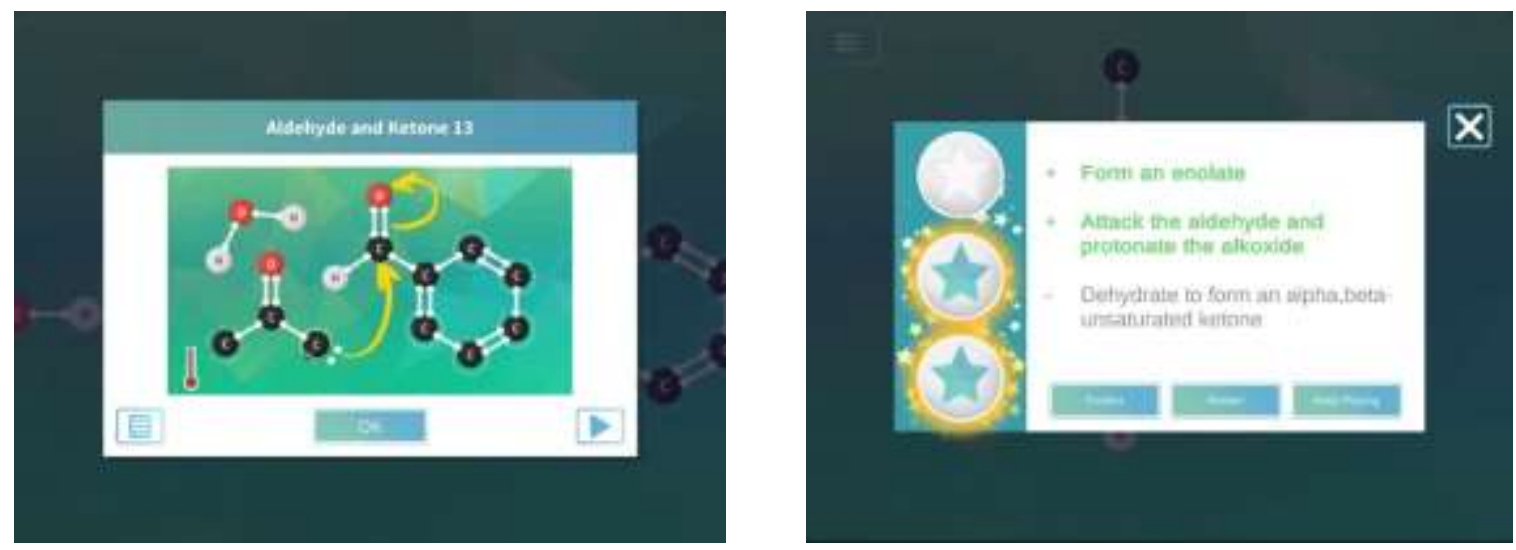

Figure 5. On the left (a) is the task card and on the right (b) is the card showing the goals for puzzle Aldehyde and Ketone 13.

Regardless of the mode, the first scaffold item, the task card, is encountered as the puzzle is opened. For Aldehyde and Ketone 13, the card depicts the second step of the mechanism (Figure 5a). Four of the six participants referred to this card as they completed the first two steps. This observation correlates to prior research 5,6 that highlights the minimal mechanistic reasoning used by students when the product is provided. From this intermediate the participants experiences vary depending on the mode.

The students in non-expert mode were able to view the next goals (Figure 5b). N3 understood the terms in the goals and was then able to use her mechanistic reasoning to hypothesize how the goals would be achieved and tested them using the app. In fact, she verbalized a preference for the app over pencil and paper because it "gives you instant feedback for what you're doing" and that you do not need to worry about "forgetting atoms" or electrons. N1 and N2 eventually concluded the goals indicated a double bond would be formed but offered little conceptual reasoning as they moved electrons to achieve this goal. 
The three students using expert mode all had different methods for solving the problem. E3, who demonstrated strong understanding, relied on identifying reactive species. She was able to finish the puzzle quickly. E1 hypothesized, incorrectly, that in the next step "a double bond will form between the carbon and the oxygen". He hit a dead-end in the app as he tried to form this intermediate. The interviewer then prompted him if he saw any "sites of reactivity". He responded, "yeah, I do actually" and was then able to move forward after the first try. This suggests that some students do not readily shift from product-oriented reasoning to mechanistic reasoning even in the absence of a product. Lastly, E2 tried many random moves. Without mechanistic knowledge or additional scaffolding, she was not able to move forward.

Another scaffold item, immediate move assessment, is identical in both modes. This formative feedback seems to be most useful, when a student is consciously moving through the puzzle. For example, N3 and E3 at some point identified multiple pathways they were considering and made a hypothesis as to which one was correct and then tested it using the app. Conversely, N2 did not seem to believe that the app was following chemical principles. When a move was wrong, he said he was "trying to think of the way it wants me to do it kind of a deal" rather than think about why that move may not be allowed. This may reflect the distrust in technology some students have from frustrating experiences in entering answer in online homework systems. It is possible that other participants had similar feelings as there were instances where a hypothesis was vocalized but not tested. Interestingly though, the hypotheses they were most reluctant to test were those that were believed to be a wrong move, indicating students need more encouragement to experiment using this environment, as was the intended purpose. Additionally, multiple participants repeated error moves, or their equivalents (such as loss of a proton) suggesting they were not learning from mistakes.

Only one participant, N2, encountered the last scaffold item, a hint, and read it correctly. This hint proved vital to help with finishing the puzzle. Although, upon completion N2 could not understand from the app alone why the final move, loss of hydroxide was allowed and even stated "Okay. Like, personally that bothers me that an $\mathrm{OH}$ is a leaving group, I get it that it happens, but it just ah...". He was not alone in questioning this step which underscores that the app is not intended to replace the instructor or the textbook. 
From this study, it was concluded that for Mechanisms to be an effective learning tool, students need to move electrons based on chemical reasoning, and explicitly told that the app can be used for discovery-based learning of EPF. With that mindset, the scaffolding embedded in Mechanisms can provide a platform for students to explore and learn mechanistic patterns. The least beneficial aspect seems to be the task card, as it can be the equivalent of giving the product which inhibits students from using mechanistic reasoning. ${ }^{5}$ When using paper assessments, many instructors are compelled to show the product of the reaction as a pathway guide and or to limit the variance in student responses. To bridge the gap between arguments for and against showing the product, we believe the remaining scaffolding features of the Mechanisms remove the need to show the product.

The goals are beneficial for guiding novice students, as they require students to interpret the language of organic chemistry and are an improvement over providing a target structure. For example, one goal in this study prompts students to think about how to achieve a dehydration which is intended to activate mechanistic reasoning. Immediate move assessment is most useful when a student has a hypothesis in mind. To encourage this practice, it is recommended that students write the next step of the mechanism on paper then test it in the app. While the evidence is yet only empirical, Wentzel has found that this instructional format improves student engagement. Additionally, students need to be reminded that the app follows the same rules as the curved arrows drawn on paper and that they are free to test moves, even to confirm the move is unallowed, using this environment. Lastly, while there are hints, it appears more are needed to help guide the most novice of students to encourage mechanistic reasoning. Currently, as an alternative to hints, the app includes a video for each puzzle that details and explains the mechanistic reasoning.

\section{INSTITUTIONAL CASE STUDIES}

The following three detailed accounts were submitted by co-authors Lawrence Yee (Hartnell College), James Kabrhel (University of Wisconsin-Green Bay), and Michael Evans (Georgia Tech) after completion of at least one full semester using Mechanisms.

1) Hartnell College is a 2-year college in Salinas, California. Lawrence Yee used the Mechanisms 
in Fall 2019 (48 students). The majority of the students in both classes were pre-med and/or biology majors, and over $90 \%$ identify as Latinx.

Reasons for using the app: "Although beginning organic chemistry students can recognize functional groups, they often have trouble knowing where to start and end a curved arrow because they have difficulty identifying a nucleophile and electrophile by looking at an organic structure. Furthermore, students frequently show bonds breaking and forming in a reaction product without showing the curved arrows that represent bonds breaking and forming and also have trouble keeping track of the number of bonds and octet rule to carbon and oxygen. The Mechanisms app gives students immediate feedback if they do not start and end their curved arrow at the correct atom. Also, students have to be able to understand common bond breaking and making processes to earn their three stars for each puzzle."

Implementation and results: "In Organic Chemistry II in Spring 2019, I assigned puzzles related to lecture content and mechanisms concepts for graded homework. There were 15 homework assignments during the semester. Each homework assignment consisted of 1 to 8 puzzles. Students were given 2 days to 12 days between the date a homework was assigned and the due date. I suggested to students to make sure they are able to draw the mechanism on paper for each reaction/puzzle using curved arrows. I did not discuss, review, or have students practice puzzles during lecture. Almost every student completed the homework assignments because the puzzles were part of their course grade, but many students did not seem to relate the puzzle solution to drawing curved arrows when describing a mechanism on paper. There was no change in overall pass rates on weekly quizzes (59\% in Spring 2018 vs. 59\% in Spring 2019).

During Organic Chemistry I in fall 2019 similar assignments were devised, but during this semester I reviewed and discussed puzzles not assigned for homework during lecture by asking the students on which atom to start and end a curved arrow. These discussions required the students to be able to identify nucleophiles and electrophiles and common bond breaking/making processes. The overall pass rates on weekly quizzes was higher using the Mechanisms app in Fall 2019 (61\%) than in Fall 2018 (52\%). Using this more active instruction using Mechanisms, it appears that students in 
Organic Chemistry I developed a better understanding of reaction mechanisms and could predict reaction products and explain product distributions more successfully.”

2) James Kabrhel used Mechanisms with students who attend the three University of WisconsinGreen Bay satellite locations (Sheboygan, Manitowoc and Marinette). These campuses serve many traditional age college students, but also returning adult students who are aiming for new degrees, or taking Organic Chemistry to prepare for a profession program like pre-Med or pre-Pharm.

Reasons for using the app: "I have been using an iPad as a pedagogical tool for the better part of a decade. I am always seeking apps that I can use to present course material in a different and modern way, and as a complement to my more traditional lectures. I had initially tested Alchemie's earlier app (Chairs ${ }^{23}$ ), so was intrigued by Mechanisms when it was released. I had also been looking for possible modeling apps to show structure and mechanisms. The combination of Mechanisms and ModelAR ${ }^{24}$ would allow me to present such concepts in 3D during class."

Implementation and results: "During the fall 2018, students could choose to complete Mechanisms puzzles to gain extra credit. This allowed me to pilot the app and also allow the developers a chance to add functionality and work out bugs. The next semester, I felt confident enough in the app to start adding Mechanisms puzzles to weekly homework assignments. Since there were basic puzzles on resonance and acid/base chemistry, I put puzzles based on those concepts starting on the second homework assignment. Before that homework assignment, I did a demonstration of the app in lecture, guiding the students through some example puzzles so they could see how the app worked. On the homework assignments where puzzles were required, I gave a point for each star earned, with each puzzle worth 3 stars.

I also assigned puzzles for the take-home final exams for both Organic Chemistry I and Organic students an alternative method to earn points, with the hope that students who struggle with writing reactions and mechanisms on paper could find a better connection with the material through the app. Anecdotally, students had a positive response to the inclusion of Mechanisms puzzles on the final exam, as it seemed provided a good balance with the other traditional, and more difficult, paper-andpencil questions. 
Through informal polling with students in Fall 2019, the overall response was positive. One student said that the app was a very useful reinforcement tool after learning the material in class. He liked that he could do puzzles for his own benefit while also getting some credit for the puzzles on the homework assignments. Some students did struggle with the interaction on a small touch screen and got frustrated when they made errors with no feedback. Most of the respondents are appreciative of the video tutorials that accompanied the puzzles. Students without a smart phone or tablet, had no problem completing the assigned puzzles on a computer. Overall, it seems as though students are using Mechanisms more as a reinforcement tool, rather than as a learning tool."

3) Georgia Tech is a large, research-active public institution in Atlanta, Georgia. Michael Evans used Mechanisms during fall 2019 in CHEM 2313 (Bioorganic Chemistry), with 70 students from a variety of majors; the top six majors represented were Biomedical Engineering, Biology, Chemical Engineering, Biochemistry, and Chemistry. A large percentage of the students aspire to careers in healthcare. The course is an equivalent alternative to a traditional Organic Chemistry II course and covers catalysis, carbonyl chemistry, the chemistry of aromatic and heteroaromatic compounds, and the structures and reactions of biomolecules.

Reason for using the app: "I became interested in the Mechanisms app as a tool for problem solving in class. My organic chemistry courses are flipped, and I felt that the problems I had been using to date could be more engaging. In Mechanisms, I saw an opportunity to help students better understand the meaning underlying curved arrows. My hope was that using it would encourage students to think mechanistically and transfer similar elementary steps across different contexts-especially the flask/cell (laboratory/biochemical) divide."

Implementation and results: "I created short assignments containing two to four problems for each class session in approximately the first two-thirds of the course. Mechanisms assignments were worth 120 of 1000 points total. Early in the semester, I designated time during class for students to work with each other on Mechanisms problems, typically after introducing relevant general information during a mini-lecture. At the end of this period, I would project the Mechanisms web application and ask students to guide me through the problems. 
Eventually, I realized that Mechanisms problems represented an opportunity to present new reactions in a dynamic and engaging format. Thus, beginning with the unit on carbonyl chemistry, I began reserving one or two problems as a means to introduce new reactions. I would simply talk through each mechanism as I dragged electrons in the app. In syncing my speech with actions in the app, I hoped that students would develop language (verbalization) associated with reaction mechanisms, reinforcing their learning in the process. I have some evidence of this development via a homework assignment that involved students generating written descriptions of reaction mechanisms without explicitly drawing curved arrows.

Themes identified in student feedback were derived from surveys, which were coded to so that frequency of the themes could be identified. Among positive feedback, a large number of students commented that the Mechanisms app helped them visualize reaction mechanisms, as they were presented in a dynamic format. Several students perceived Mechanisms problems to be more accessible than similar problems on paper, although poor translation of performance in Mechanisms to paper-based problems was an issue for some students. Several students made it apparent that Mechanisms facilitated their independent learning, although a roughly equal number commented that they did not feel that they learned from Mechanisms.

Among negative feedback, students' most common complaint was that the app was "touchy," particularly on smartphone screens. At the relatively small scale of a phone screen, electrons were sometimes difficult to manipulate. A few students noted glitches; for example, electron flows involving large molecules sometimes resulted in a "tangling" of bonds and atoms. Several students commented that the organization of assignments within the app made deadlines unclear or difficult to see; a few requested notifications from the app as assignment deadlines approached. Some students felt that "correct" mechanistic pathways were too restrictive, particularly in cases when valid alternative resonance forms could be generated.

I found that using the Mechanisms app facilitated my students working with and thinking in reaction mechanisms because it dramatically lowered the barrier to "drawing" them. The Mechanisms app makes the prospect of generating a reaction mechanism seem much less daunting than staring at a blank piece of paper with a reaction scheme at the top. When I teach this course again, I will 
probably make a concerted effort to have students talk through Mechanisms problems with each other in class. I will also ask students to translate Mechanisms solutions into curved-arrow mechanisms on paper."

\section{CONCLUSIONS AND NEXT STEPS}

In Process of Education, ${ }^{19}$ Jerome Bruner stated, "The shrewd guess, the fertile hypothesis, the courageous leap to a tentative conclusion - these are the most valuable coins of the thinker at work."

One of the common themes running through the student use, student usability, and instructor case studies is the reticence of students to embrace the "failure" that is an inherent part of play and experimentation. Author Michael Evans remarked that at Georgia Tech "it was unclear to some students whether the app was a learning tool or an assessment tool."

The next steps in the development of Mechanisms will be to create a means for the formative feedback delivered through the interface to feel more like a puzzle to be solved and less like a test of knowledge, to help create a more natural way for students to embrace the trial and error of experiential learning. One method currently being researched by the development and pedagogy team is through data analytics and machine learning. Through analysis of the moves collected from past users, it is the intention that Mechanisms will be able to tailor the individual experience based on a users' performance through an automatic variation of the level of scaffolding provided to the student. With a more personalized formative assessment mode, this and future software applications will help to students to take that "courageous leap" needed for meaningful learning and academic growth.

\section{ASSOCIATED CONTENT}

Supporting Information

The Supporting Information is available in this DropBox Folder:

https://www.dropbox.com/sh/j576ftaqs11n6n5/AADtKdj8c9VMgF8qurLear2ya?dl=0

In the folder is the Mechanisms Puzzle Finder spreadsheet with detailed entries on the pedagogical content of the app.

\section{AUTHOR INFORMATION}

Corresponding Author

*E-mail: Julia@alchem.ie 
ORCID

Notes

Authors Julia Winter, Sarah Wegwerth, and Gianna Manchester have received compensation for work performed as employees or contractors of Alchemie, the producer of Mechanisms.

Authors Michael T. Wentzel, Michael J. Evans, James Kabrhel, and Lawrence J. Yee declare no competing interests.

\section{ACKNOWLEDGMENTS}

We would like to thank Augsburg University alumnus, Isaiah Ripley, for his work in transcribing the student interviews in the usability study.

This work has been supported through grants to Alchemie from the National Science Foundation Small Business Innovation Research program, Phase I \#1548225 and Phase II \#1659983.

\section{REFERENCES}

(1) Bhattacharyya, G. From Source to Sink: Mechanistic Reasoning Using the Electron-Pushing Formalism. Journal of Chemical Education 2013, 90 (10), 1282-1289. https://doi.org/10.1021/ed300765k.

(2) Bhattacharyya, G. Trials and Tribulations: Student Approaches and Difficulties with Proposing Mechanisms Using the Electron-Pushing Formalism. Chemistry Education Research and Practice 2014, 15 (4), 594-609. https://doi.org/10.1039/c3rp00127j.

(3) M. Duis, J. Organic Chemistry Educators' Perspectives on Fundamental Concepts and Misconceptions: An Exploratory Study. Journal of Chemical Education 2011, 88 (3), 346-350. https://doi.org/10.1021/ed1007266.

(4) Bhattacharyya, G.; M. Bodner, G. "It Gets Me to the Product": How Students Propose Organic Mechanisms. Journal of Chemical Education 2005, 82 (9). https://doi.org/10.1021/ed082p1402.

(5) DeCocq, V.; Bhattacharyya, G. TMI (Too Much Information)! Effects of given Information on Organic Chemistry Students' Approaches to Solving Mechanism Tasks. Chemistry Education Research and Practice 2019, 20 (1), 213-228. https:/ / doi.org/ 10.1039/C8RP00214B.

(6) Grove, N. P.; Cooper, M. M.; Rush, K. M. Decorating with Arrows: Toward the Development of Representational Competence in Organic Chemistry. Journal of Chemical Education 2012, 89 (7), 844-849. https://doi.org/10.1021/ed2003934.

(7) Ferguson, R.; Bodner, G. M. Making Sense of the Arrow-Pushing Formalism among Chemistry Majors Enrolled in Organic Chemistry. Chem. Educ. Res. Pract. 2008, 9 (2), 102-113. 
(8) Grove, N. P.; Cooper, M. M.; Cox, E. L. Does Mechanistic Thinking Improve Student Success in Organic Chemistry? Journal of Chemical Education 2012, 89 (7), 850-853.

https://doi.org/10.1021/ed200394d.

(9) Stowe, R. L.; Cooper, M. M. Practicing What We Preach: Assessing "Critical Thinking" in Organic Chemistry. Journal of Chemical Education 2017, 94 (12), 1852-1859.

https://doi.org/10.1021/acs.jchemed.7b00335.

(10) Crandell, O. M.; Lockhart, M. A.; Cooper, M. M. Arrows on the Page Are Not a Good Gauge: Evidence for the Importance of Causal Mechanistic Explanations about Nucleophilic Substitution in Organic Chemistry. Journal of Chemical Education 2020.

https://doi.org/10.1021/acs.jchemed.9b00815.

(11) Flynn, A. B.; Ogilvie, W. W. Mechanisms before Reactions: A Mechanistic Approach to the Organic Chemistry Curriculum Based on Patterns of Electron Flow. Journal of Chemical Education 2015, 92 (5), 803-810. https://doi.org/10.1021/ed500284d.

(12) Webber, D. M.; Flynn, A. B. How Are Students Solving Familiar and Unfamiliar Organic Chemistry Mechanism Questions in a New Curriculum? Journal of Chemical Education 2018, 95 (9), 1451-1467. https://doi.org/10.1021/acs.jchemed.8b00158.

(13) Anzovino, M. A.; Bretz, S. L. Organic Chemistry Students' Ideas about Nucleophiles and Electrophiles: The Role of Charges and Mechanisms. Chem. Educ. Res. Pract., 2015, 16, 797810.

(14) Flynn, A. B. ;; Featherstone, R. B. Language of Mechanisms: Exam Analysis Reveals Students' Strengths, Strategies, and Errors When Using the Electron-Pushing Formalism (Curved Arrows) in New Reactions. Chem. Educ. Res. Pract. 2017, 18 (1), 64-77.

(15) Graulich, N.; Schween, M. Concept-Oriented Task Design: Making Purposeful Case Comparisons in Organic Chemistry. Journal of Chemical Education 2018, 95 (3), 376-383. https://doi.org/10.1021/acs.jchemed.7b00672.

(16) Galloway, K. R.; Leung, M. W.; Flynn, A. B. A Comparison of How Undergraduates, Graduate Students, and Professors Organize Organic Chemistry Reactions. Journal of Chemical Education 2018, 95 (3), 355-365. https://doi.org/10.1021/acs.jchemed.7b00743.

Bongers, A.; Beauvoir, B.; Streja, N.; Northoff, G.; Flynn, A. B. Building Mental Models of a Reaction Mechanism: The Influence of Static and Animated Representations, Prior Knowledge, and Spatial Ability. Chemistry Education Research and Practice 2020. https://doi.org/10.1039/c9rp00198k.

(18) E. Winter, J.; E. Wegwerth, S.; A. Morsch, L.; DeSutter, D.; M. Goldman, L.; M. Reutenauer, L.; K. DeKorver, B. The Mechanisms App and Platform: A New Game-Based Product for Learning Curved Arrow Notation; 2019. https://doi.org/10.1021/bk-2019-1336.ch007.

(19) Jerome Bruner. The Process of Education; Harvard University Press, 1960. 
(20) Mechanisms. Alchemie Solutions, Inc. https://www.alchem.ie/mechanisms (accessed Feb 12, 2020).

415 (21) Mechanisms Web-version https://alchemie-mechanisms.firebaseapp.com/.

(22) Rahul Vohra. How Super Human Built an Engine to FInd Product-Market Fit https: / firstround.com/review/how-superhuman-built-an-engine-to-find-product-market-fit/ (accessed Feb 12, 2020).

(23) Winter, J.; Wentzel, M.; Ahluwalia, S. Chairs!: A Mobile Game for Organic Chemistry Students To Learn the Ring Flip of Cyclohexane. Journal of Chemical Education 2016, 93 (9), 1657-1659. https://doi.org/10.1021/acs.jchemed.5b00872.

(24) ModelAR. Alchemie Solutions, Inc. https://www.alchem.ie/modelar/game (accessed Feb 12, 2020). 